\title{
Oscilações hidroclimáticas associadas às condições ambientais: bacia hidrográfica do rio Canoas-SC
}

\author{
Hydroclimatic oscillations associated to environmental conditions: \\ watershed of Canoas-SC river
}

\section{Dênis José Cardoso Gomes"(i), Camila do Socorro Teixeira Soares'i(D, Ingrid Cássia Porto Lima'(i), Nedilson Sanches Ferreira' ${ }^{1}$, Aline Maria Meiguins de Lima'}

'Universidade do Estado do Pará, Belém, PA, Brasil

"Universidade Federal do Pará, Belém, PA, Brasil

\section{RESUMO}

A Precipitação relacionada a condicionantes ambientais é determinante para a compreensão da dinâmica hidrológica em bacias hidrográficas. O objetivo deste trabalho consiste em analisar a variabilidade hidroclimática e condicionantes ambientais da bacia hidrográfica do rio Canoas-SC, caracterizando as áreas de maior e/ou menor vulnerabilidade climática. Utilizou-se o Índice Oscilação Sul, Oscilação da Antártica e Modo Meridional do Atlântico (National Oceanic Atmospheric and Administration); dados hidrometeorológicos (Agência Nacional de Águas); relevo (Instituto Nacional de Pesquisas Espaciais); uso e ocupação da terra (Ministério do Meio Ambiente). Adotou-se a Ponderação Regional, Índice de Anomalia de Chuva, Regionalização de vazão e o Índice de Pearson. As maiores precipitações foram em 2015 (2210,6 mm) e as menores em 1988 (1301,2 mm). O trimestre mais chuvoso é Dezembro-Janeiro-Fevereiro e o menos chuvoso Junho-Julho-Agosto, com as cheias no Alto Canoas (Setembro-Outubro-Novembro) e estiagem no Baixo Canoas (Março-Abril-Maio). A precipitação anual varia no sentido leste $(1750,1 \mathrm{~mm})$ a oeste $(1883,1 \mathrm{~mm})$. A bacia apresenta uma boa correlação da precipitação com o conjunto cota $x$ vazão, já com os índices foi fraca. As formas de uso da terra e as variações altimétricas influenciam no padrão hidroclimático, sendo os extremos de estiagem e as enxurradas os desastres mais frequentes.

Palavras-chaves: Clima; Meio Ambiente; Precipitação 


\section{ABSTRACT}

The rainfall related to environmental conditions is decisive for understanding the hydrological dynamics in watersheds. The objective of this work is to analyze the hydroclimatic variability and environmental conditions of the Canoas-SC river basin, characterizing the areas of greatest and / or least climatic vulnerability. The South Oscillation Index, Antarctic Oscillation and Atlantic Meridional Mode (National Oceanic Atmospheric and Administration); rainfall data (National Water Agency), relief (National Institute for Space Research), land use and occupation (Ministry of the Environment) was used. The Regional Weighting, Rain Anomaly Index, Flow Regionalization and Pearson Index were adopted. The highest rainfall was in 2015 (2210.6 $\mathrm{mm}$ ) and the lowest in $1988(1301.2 \mathrm{~mm})$. The rainiest quarter is DecemberJanuary-February and the least rainy June-July-August, with floods in Alto Canoas (September-OctoberNovember) and drought in Baixo Canoas (March-April-May). Annual precipitation varies from east (1750.1 $\mathrm{mm}$ ) to west $(1883.1 \mathrm{~mm})$. The basin has a good correlation of precipitation with the quota $\times$ flow set, with the indices being weak. The forms of land use and altimetric variations influence the hydroclimatic pattern, with drought extremes and runoffs being the most frequent disasters.

Keywords: Climate; Environment; Rainfall

\section{INTRODUÇÃO}

O acelerado e desordenado processo de crescimento populacional no mundo tem provocado vastos problemas ambientais, pois os efeitos causados por atividades antrópicas resultam, entre outros, alterações climáticas nas mais variadas escalas espaço-temporais (REIS et al., 2016). Estas modificações do meio ambiente, mas especificamente em bacias hidrográficas influenciam diretamente no ciclo hidrológico regional, podendo ocasionar consequências ambientais negativas (ANDRADE et al., 2012), como inundações e enxurradas.

Em paralelo aos impactos antropogênicos, os extremos climáticos são a componente do acoplamento oceano-atmosfera que influenciam no desencadeamento dos desastres, em que tais oscilações podem ser monitoradas por meio dos índices climáticos. Como a Oscilação da Antártica (OAA), que é a diferença de pressão atmosférica relacionada ao nível do mar nas latitudes nas regiões polares, onde há um centro de baixa pressão no Pólo Sul gerando centros de alta pressão nas latitudes médias e suas anomalias positivas favorecem a estiagem na América do Sul (DULTRA; ROMERO, 2017); o Modo Meridional do Atlântico (AMM) é definido por um gradiente inter-hemisférico (Norte-Sul) de 
Temperatura da Superfície do Mar (TSM), no qual em sua fase positiva (negativa) a TSM caracteriza-se para o Atlântico tropical norte positiva (negativa) e para o Atlântico tropical sul sinais opostos (HOUNSOU-GBO, 2015); e o Índice Oscilação Sul (IOS) é um indicador de fenômenos (ENOS) de grande escala da interação oceano-atmosfera caracterizado pela diferença de pressão em relação ao nível do mar entre o Pacífico central (Taiti) e oeste (Darwin) provocando aumento ou diminuição da magnitude dos ventos alísios sobre o Pacífico equatorial (CERA; FERRAZ, 2015; RAMÓN-VALENCIA et al., 2019).

Deste modo, segundo Ribeiro et al. (2017) as ocorrências dos desastres naturais estão mais frequentes nos últimos anos em todo mundo, sendo classificado como tal quando atingem a população, interrompendo temporariamente ou permanentemente, a normalidade e desenvolvimento da sociedade impactada. Souza et al. (2017) complementam que Santa Catarina apresenta um alto número de eventos ocorridos desde 1991 de inundação (2781 casos) e estiagem, e ainda apontam o agravamento destes desastres por fatores antrópicos como o uso e ocupação do solo na várzea em terrenos acidentados onde são vulneráveis a inundações, destacando que em bacia hidrográficas pequenas há um maior escoamento superficial sobre o solo devido a declividade acentuada, provocando uma drenagem elevada e suscetibilizando a região á fenômenos de enxurradas (LICCO et al., 2015).

Assim, estudos hidrológicos associados aos fatores ambientais são cruciais para e prevenção desses eventos e de acordo com Capozzoli et al. (2017) o regime fluvial de um rio está relacionado com a interação entre o clima e a morfologia de uma bacia hidrográfica, ressaltando a análise dos índices climáticos que influenciam no padrão hidrológico regional, além da importância do monitoramento pluviométrico nas áreas próxima da bacia, pois dependendo das condições de infiltração, pode alterar a variabilidade fluviométrica da rede 
hidrográfica. Nesta mesma linha de pensamento, Cataldi et al. (2010) discutem que há poucos estudos relacionando mecanismos climáticos extratropicais com os sistemas hidrológicos da América do Sul. Conforme pesquisas feitas por Muniz e Filizola Junior (2012), a cota fluviométrica pode ser entendida como a altura do nível d' água de uma seção em relação a uma referência medida por uma régua linimétrica. Silva (2013) reforça a importância do estudo da variabilidade climática associada ao regime fluviométrico no monitoramento e prevenção de eventos de desastres naturais como secas e cheias extremas, inundações ocorridas periodicamente na cidade de Blumenau-SC (clima similar a sub-bacia do rio Canoas).

Os Modelos Digitais de Elevação (MDE) correspondem a representação do relevo de uma superfície onde pode-se definir a direção do fluxo da água, delimitar bacias hidrográficas e calcular as áreas de contribuição de forma eficiente a partir da geomorfologia da região podendo extrair informações hidrológicas consistentes (MARION et al., 2015). Para Peluso Junior (1986) o território catarinense é caracterizado por um altiplano com baixo grau de declividade (oeste) e uma região de planaltos que se estende até a encosta (leste) do estado. Com este agravante geomorfológico, Seluchi et al. (2017) comentam que Santa Catarina é o terceiro estado brasileiro com maior número de frequência de desastres naturais devido sua localização em latitudes médias e subtropicais sofrendo influência de sistemas frontais, jatos de altos e baixos níveis, além de sua proximidade com o oceano Atlântico propiciando um cenário favorável a tempestades severas desencadeadoras de desastres naturais.

Diante do exposto, objetivo deste trabalho consiste em analisar a variabilidade hidrológica associada à índices climáticos (AMM, IOS, OAA) e condicionantes ambientais da bacia hidrográfica do rio Canoas, caracterizando as áreas de maior e/ou menor vulnerabilidade hidroclimática. 


\section{MATERIAL E MÉTODOS}

\section{1 Área de estudo}

A bacia hidrográfica do rio Canoas $(\mathrm{BHC})$ está inserida completamente no estado de Santa Catarina com uma população de aproximadamente 412.653 hab. (Fig. 1), abrangendo uma área de $14.898,0 \mathrm{Km}^{2}$, onde o rio Canoas nasce (leste) próximo ao município de Urubici até a sua confluência com o rio Pelotas (oeste), sendo seus maiores afluentes o rio das Caveiras a margem esquerda e o rio Marombas a direita (MINISTÉRIO DO MEIO AMBIENTE, 2006). As sedes municipais situadas na BHC são descritas na Tabela 3.

Figura 1 - Localização da área de estudo e estações hidrológicas: bacia hidrográfica do rio Canoas

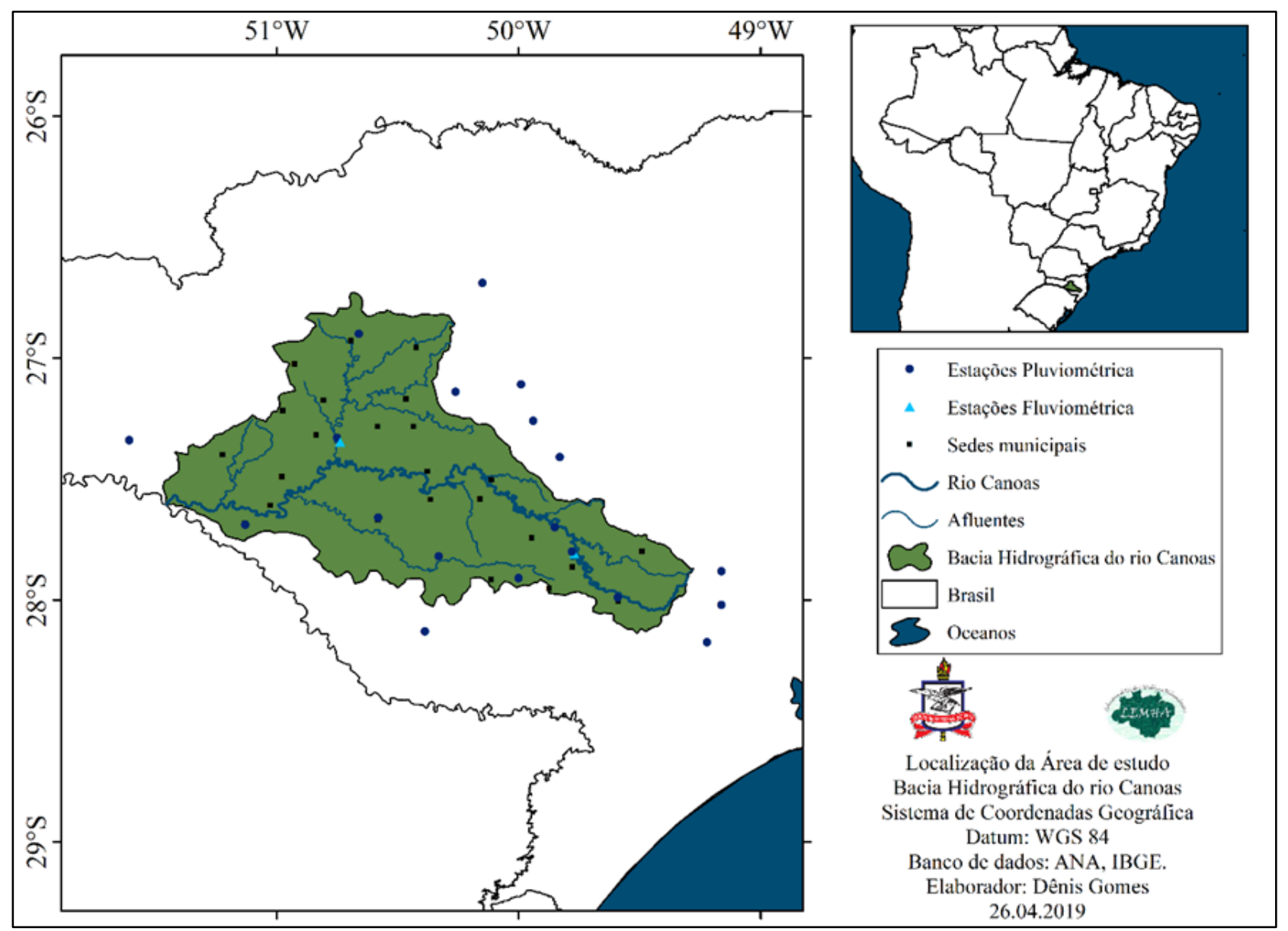


Fonte: Autores (2020)

A climatologia da região é caracterizada por precipitações anuais variando de $1650 \mathrm{~mm}$ - $1850 \mathrm{~mm}$, com temperaturas do ar mínimas de $10{ }^{\circ} \mathrm{C}$ e máximas de $23^{\circ} \mathrm{C}$, umidade relativa do ar em torno de $76^{\circ} \mathrm{C}$ e ventos de noroeste de magnitude $3 \mathrm{~m} / \mathrm{s}$ (INMET, 2019).

\subsection{Aquisição de dados}

A National Oceanic and Atmospheric Administration (NOAA, 2018) disponibiliza dados da média trimestral do Índice Oceânico Niño (IOS), Oscilação Antártica (OAA) e Modo Meridional do Atlântico (AMM).

Os dados pluviométricos e fluviométricos foram obtidos no banco de dados da série histórica da Agência Nacional da Águas (ANA) disponibilizados na plataforma HidroWeb, utilizando somente os dados consistentes (baixa ocorrência de falhas) de um período de 30 anos (1988 a 2017) com um número de 19 estações pluviométricas e 2 estações fluviométricas (Tab. 1) dispostas dentro e algumas nas proximidades (ao redor) da BHC.

Para visualização da altimetria da bacia foram utilizados os dados da missão SRTM (Shuttle Radar Topography Mission) que são fornecidos pelo Instituto Nacional de Pesquisas Espaciais (INPE, 2018) através da plataforma TOPODATA, para gerar os Modelos Digitais de Elevação (MDE) (VALERIANO; ROSSETTI, 2012; LEDA et al., 2015). Para Correa et al. (2017), os MDE's são um aporte de ferramentas na análise de uma bacia hidrográfica possibilitando a delimitação espacial dos divisores de bacia, e ainda destacam estes dados provenientes da missão SRTM como um dos mais eficientes utilizados. Os diferentes usos e ocupação do solo foram confeccionados de acordo com os utilizados pelo Ministério do Meio Ambiente (MMA, 2019). 
Tabela 1 - Informações das estações hidrológicas utilizadas

\begin{tabular}{|c|c|c|c|c|c|c|c|}
\hline $\begin{array}{l}\text { Estações } \\
\text { Pluviométrica }\end{array}$ & Código & $\begin{array}{c}\text { Estações } \\
\text { Pluviométrica }\end{array}$ & Código & $\begin{array}{c}\text { Estações } \\
\text { Pluviométrica }\end{array}$ & Código & $\begin{array}{l}\text { Estações } \\
\text { Fluviométrica }\end{array}$ & Código \\
\hline Nova Cultura & 2650023 & Agrolândia & 2749041 & Painel & 2750007 & Vila Canoas & 71200000 \\
\hline Lebon Regis & 2650019 & Barracão & 2749014 & Urubici & 2749054 & $\begin{array}{c}\text { Passo } \\
\text { Marombas }\end{array}$ & 71498000 \\
\hline Taío & 2749003 & $\begin{array}{l}\text { São José do } \\
\text { Cerrito }\end{array}$ & 2750020 & Coxilha Rica & 2850004 & - & - \\
\hline $\begin{array}{l}\text { Cabeceira } \\
\text { Ribeirão } \\
\text { Caetano }\end{array}$ & 2750021 & Anita Garibaldi & 2751001 & $\begin{array}{l}\text { Santa Rosa de } \\
\text { Lima }\end{array}$ & 2849031 & - & - \\
\hline $\begin{array}{l}\text { Pouso } \\
\text { Redondo }\end{array}$ & 2749006 & Rio Bonito & 2749009 & Rio Pequeno & 2849008 & - & - \\
\hline $\begin{array}{l}\text { Passo } \\
\text { Marombas }\end{array}$ & 2750009 & Vila Canoas & 2749031 & - & - & - & - \\
\hline Capinzal & 2751012 & Anitapolis & 2749027 & - & - & - & - \\
\hline
\end{tabular}

Fonte: ANA (2019). Adaptado por autor (2019)

\subsection{Procedimentos metodológicos}

Utilizou-se o programa Hidro 1.3 (ANA) para a visualização dos dados pluviométricos e posteriormente exportou-se para planilhas de dados para organização e tratamento. A técnica de Ponderação Regional (Eq. 1) foi usada para o preenchimento das falhas observadas (CURTARELLI et al., 2010; PENEREIRO et al., 2018).

$$
P(x)=\frac{1}{3}\left(\frac{N x}{N a} P a+\frac{N x}{N b} P b+\frac{N x}{N c} P c\right)
$$

Onde: $\mathrm{N} x$ é a precipitação mensal do posto pluviométrico que há falha; $\mathrm{N} a$, $\mathrm{N} b$ e Nc é a precipitação média mensal dos postos pluviométricos próximos; $\mathrm{P} a, \mathrm{P} b$ e Pc é a precipitação do mês dos postos pluviométricos próximos.

Calculou-se o Índice de Anomalia de Chuva (IAC) para verificar-se o potencial hídrico da BHC conforme a Eq. 2 (Anomalias positivas) e a Eq. 3 (Anomalias 
negativas) determinadas por Rooy (1965), sendo adaptadas e testadas posteriormente por Freitas (2005), Marcuzzo et al. 2011, Gross e Cassol (2015), Noronha et al. (2016) e Cury et al. (2018).

$$
\begin{gathered}
I A C=3\left[\frac{(N-\bar{N})}{(M-\bar{N})}\right] \\
I A C=-3\left[\frac{(N-\bar{N})}{(X-\bar{N})}\right]
\end{gathered}
$$

Onde: $\mathrm{N}=$ Precipitação observada atual $\left(\mathrm{mm} \cdot \mathrm{mês}^{-1}\right) ; \bar{N}=$ Precipitação média mensal da série histórica $(\mathrm{mm}) ; \mathrm{M}=$ Média das dez maiores precipitações mensais da série histórica; $X$ = Média das dez menores precipitações mensais da série histórica.

Os Índices de Anomalias de Chuva (IAC) são classificados de acordo com Freitas (2005) e Fernandes et al. (2009) em suas respectivas intensidades (Tab. 2).

Tabela 2 - Classificação do Índice de Anomalia de Chuva

\begin{tabular}{lc}
\hline \multicolumn{1}{r}{ Índice de Anomalia de Chuva (IAC) } & Classificação Pluviométrica \\
\hline$\geq 4$ & Extremamente Chuvoso \\
$\mathbf{2}>\mathbf{4}$ & Muito Chuvoso \\
$\mathbf{0}>\mathbf{2}$ & Chuvoso \\
$\mathbf{0}<-\mathbf{2}$ & Seco \\
$-\mathbf{- 2}<-\mathbf{4}$ & Muito Seco \\
$\leq-\mathbf{4}$ & Extremamente Seco \\
\hline
\end{tabular}

Fonte: Autor (2020). Adaptado de Araújo et al. (2009) e Noronha et al. (2016)

Realizou-se a padronização das variáveis hidroclimáticas para posteriormente calcular o coeficiente de correlação de Pearson $(r)$ representado pela Eq. 4 e coeficiente de determinação $\left(r^{2}\right)$ para averiguar o grau de relação dos 
dados de TSM, precipitação, cota e vazão e o quanto a variável oceânica influencia na hidrologia da região (FRANCA; MENDONÇA, 2016; GOMES et al., 2019).

$$
r=\frac{\sum(X-\bar{X}) \cdot(Y-\bar{Y})}{\sqrt{\sum(X-\bar{X})^{2} \cdot \sum(Y-\bar{Y})^{2}}}
$$

Onde: $\mathrm{N}=$ número de pares de dados; $\Sigma \mathrm{xy}=$ soma do produto das variáveis “x” e "y"; $\Sigma x=$ soma da variável “ $x " ; \Sigma y=$ soma da variável "y" .

Segundo Dias et al. (2020) o coeficiente de correlação linear de Pearson é um indicador estatístico que calcula a correlação entre as variáveis $\mathrm{X}$ e Y. O $\mathrm{r}=1$ é indica a correlação linear perfeita positiva entre as variáveis. A correlação linear perfeita negativa é quando $r=-1$. Quando se tem $r=0$ não existe correlação entre as variáveis em estudo (DIAS et al., 2020). A análise correlacional indica a relação entre 2 variáveis lineares e os valores sempre serão entre +1 e -1 . O sinal indica a direção, se a correlação é positiva ou negativa e o tamanho variável indica a força da correlação.

A expressão do $r^{2}$ (Eq. 5) mostra que o coeficiente de determinação $\left(r^{2}\right)$ é sempre um número positivo entre zero e um, que quanto maior for o $\mathrm{r}^{2}$, melhor será o poder de explicação da reta de regressão. Logo: corresponde à variação explicada e a variação não explicada (CHENG et al., 2014).

$$
r^{2}=\frac{\sum_{i=1}^{n}\left(\widehat{Y}_{I}-\bar{Y}\right)^{2}}{\sum_{i=1}^{n}\left(Y_{I}-\bar{Y}\right)^{2}}
$$

A topografia regional e o uso e cobertura da terra foram analisados para verificar-se as condições de terreno no qual a BHC localiza-se, visando uma melhor compreensão dos fatores ambientais em que a BHC está submetida, segundo sua variabilidade hidrológica (BALBINOT et al., 2008; OLIVEIRA; MARCUZZO, 2013; GOMES et al., 2018).

A partir dos dados coletados, os mesmos foram organizados e calculados parâmetros estatísticos (médias e correlações) gerando figuras representativas 
para investigar observacionalmente o quanto os índices climáticos (OAA, AMM e IOS) associadas a alguns tipos de configurações de terreno podem estar influenciando a variabilidade hidrológica da bacia hidrográfica do rio Canoas (OLIVEIRA; MARCUZZO，2013; NÓBREGA; SANTIAGO, 2014; DULTRA; ROMERO, 2017).

$\mathrm{Na}$ avaliação das vazões de referência foi adotado o procedimento de Curtarelli (2010) e também usado por Garbossa e Pinheiro (2015) que apresentam uma equação de regionalização para o estado de Santa Catarina, além da análise de desvio entre a vazão observada (medida) e a estimada pela regionalização, conforme as Eq. 6 e 7.

$$
\begin{gathered}
Q_{M L T}=1,2410^{-4} P^{0,759} A B^{0,968} \\
D \%=\frac{Q_{r}-Q_{m-t}}{Q_{r}}
\end{gathered}
$$

Sendo, QмLт é a vazão específica média de longo termo $\left(\mathrm{m}^{3} / \mathrm{s}\right)$; $\mathrm{P}$ é a precipitação anual média na bacia contribuinte (mm/ano) e $A B$ é a área de drenagem da bacia contribuinte $\left(\mathrm{km}^{2}\right)$; Qr é a vazão calculada com a equação de regionalização e $\mathrm{Q}_{\mathrm{m}-\mathrm{t}}$ é a vazão medida, para cada instante de tempo t.

\section{RESULTADOS E DISCUSSÕES}

A Fig. 2 destaca a variabilidade anômala dos índices climáticos nos oceanos Pacífico Sul (IOS) e Atlântico (AMM e OAA), no qual observa-se anomalias positivas da região polar e tropical, sendo destaque os anos de 1998 (0,78 hPa) e 2010 (0,74 hPa) para a região Antártica, assim como $2005\left(3,67^{\circ} \mathrm{C}\right)$ e $2010\left(4,98^{\circ} \mathrm{C}\right)$ oriundas das águas do Atlântico tropical, marcando-os como os maiores extremos positivos e desfavorecendo a precipitação nesses períodos para o continente Sul-Americano. Em contrapartida, nestas mesmas áreas há a ratificação do raciocínio pretérito, quando se observa nos últimos anos as anomalias de resfriamento com os 
extremos em $1993\left(-3,04{ }^{\circ} \mathrm{C}\right)$ e $1994\left(-3,51^{\circ} \mathrm{C}\right)$ para o atlântico tropical, além de pressões anômalas em $1992(-0,64 \mathrm{hPa})$ e 2002 (- 0,60 hPa) para o polo sul, indicando o favorecimento do aumento pluvial para a América do Sul.

No oceano Pacífico tropical observa-se uma variação irregular da anomalia barométrica, onde verifica-se os valores positivos extremos nos anos de 2008 (1,88 hPa) e 2011 (2,31 hPa), condições favoráveis a ocorrência do fenômeno da La Niña. Além disto, pressões anomalamente negativas foram observadas em 1992 (- 1,37 hPa) e 1994 (- 1,37 hPa), caracterizando a tendência desses anos a eventos de El Niño.

Figura 2 - Anomalias dos Índices Climáticos (1988 - 2017): Oceano Atlântico (OAA e AMM). Oceano Pacífico (IOS)

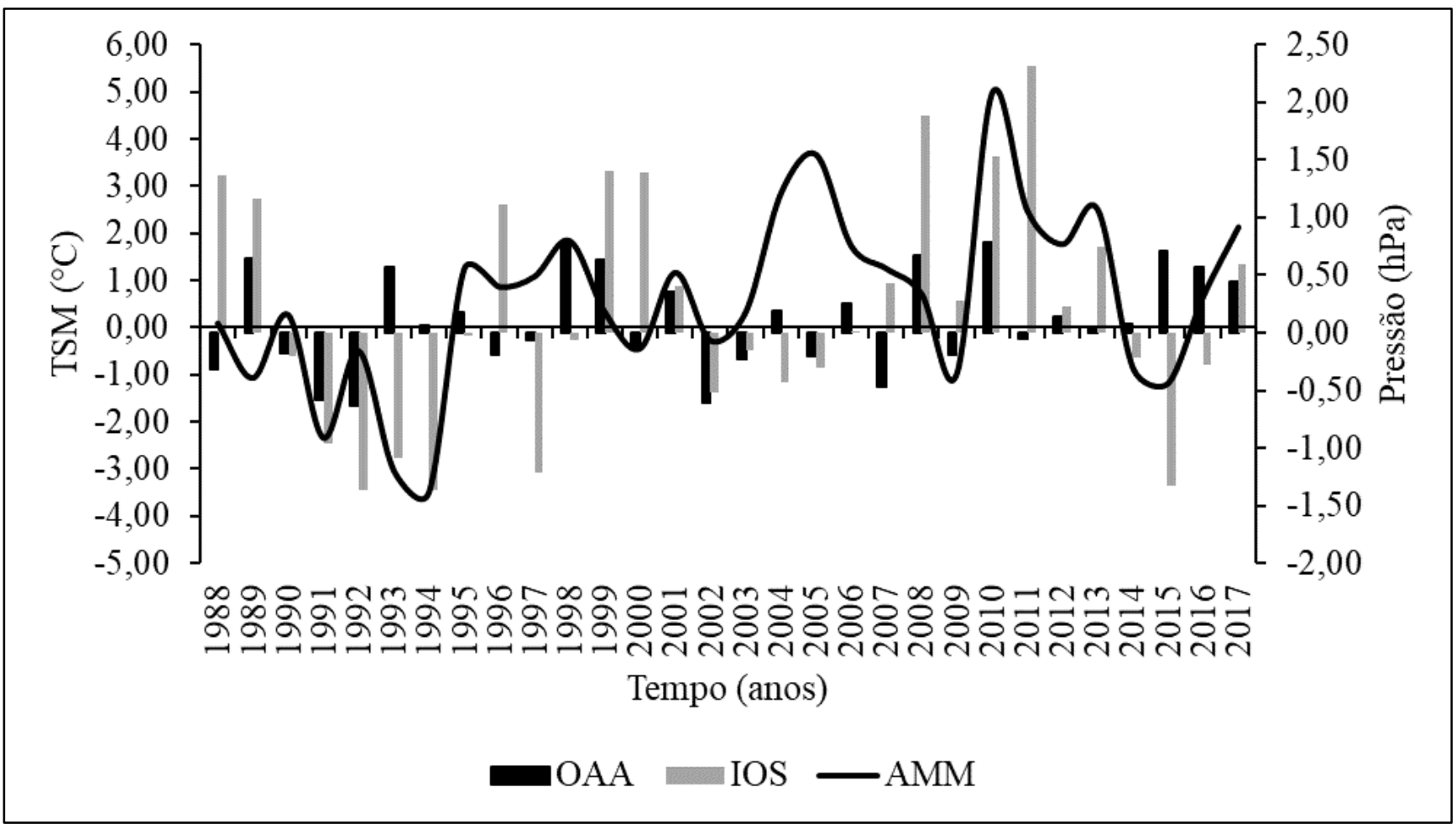

Fonte: NOAA (2019). Adaptado por autor (2019)

A Fig. 3 descreve a variabilidade pluviométrica anual na BHC entre os anos de 1988 e 2017, onde se verificou elevados volumes de chuva ao longo do ano inteiro durante todo o período dos 30 anos analisados. Tal observação, pode ser explicada devido a região ser propicia a formação de nebulosidade e a 
disponibilidade de umidade sobre o local, além dos altiplanos característicos da área. Os maiores valores de precipitação foram observados no ano de 2015 (2.210,6 mm), onde mesmo com a anomalias positiva da região polar e as águas superficiais anomalamente quentes advindas do Atlântico tropical contribuírem para estiagem das chuvas, as pressões anômalas negativas do Pacífico tropical (maior extensão superficial oceânica) favorecem o fenômeno de El Niño aumentando a pluviosidade na região sul. O Sistema Nacional de Proteção da Defesa Civil (SNPDC, 2020) constatou eventos de chuvas intensas em Abdon Batista no verão austral de 2015.

Os menores valores pluviométricos foram vistos no ano de 1988 com valores de 1.301,2 mm, apesar das anomalias positivas de pressão do Pacífico, assim como os valores negativos da Antártica e do Atlântico tropical favorecerem o aumento pluvial. Correa e Galvani (2017) destacaram a importância da variabilidade da precipitação para ajudar no entendimento da dinâmica climática e hídrica em bacias hidrográficas. Estudos realizados por Sousa et al. (2017) sugerem a influência da variabilidade interanual da TSM do oceano Pacífico na precipitação e vazão de bacias hidrográficas da América do Sul.

Figura 3 - Anomalias dos Índices Climáticos (1988 - 2017): Oceano Atlântico (OAA e AMM). Oceano Pacífico (IOS)

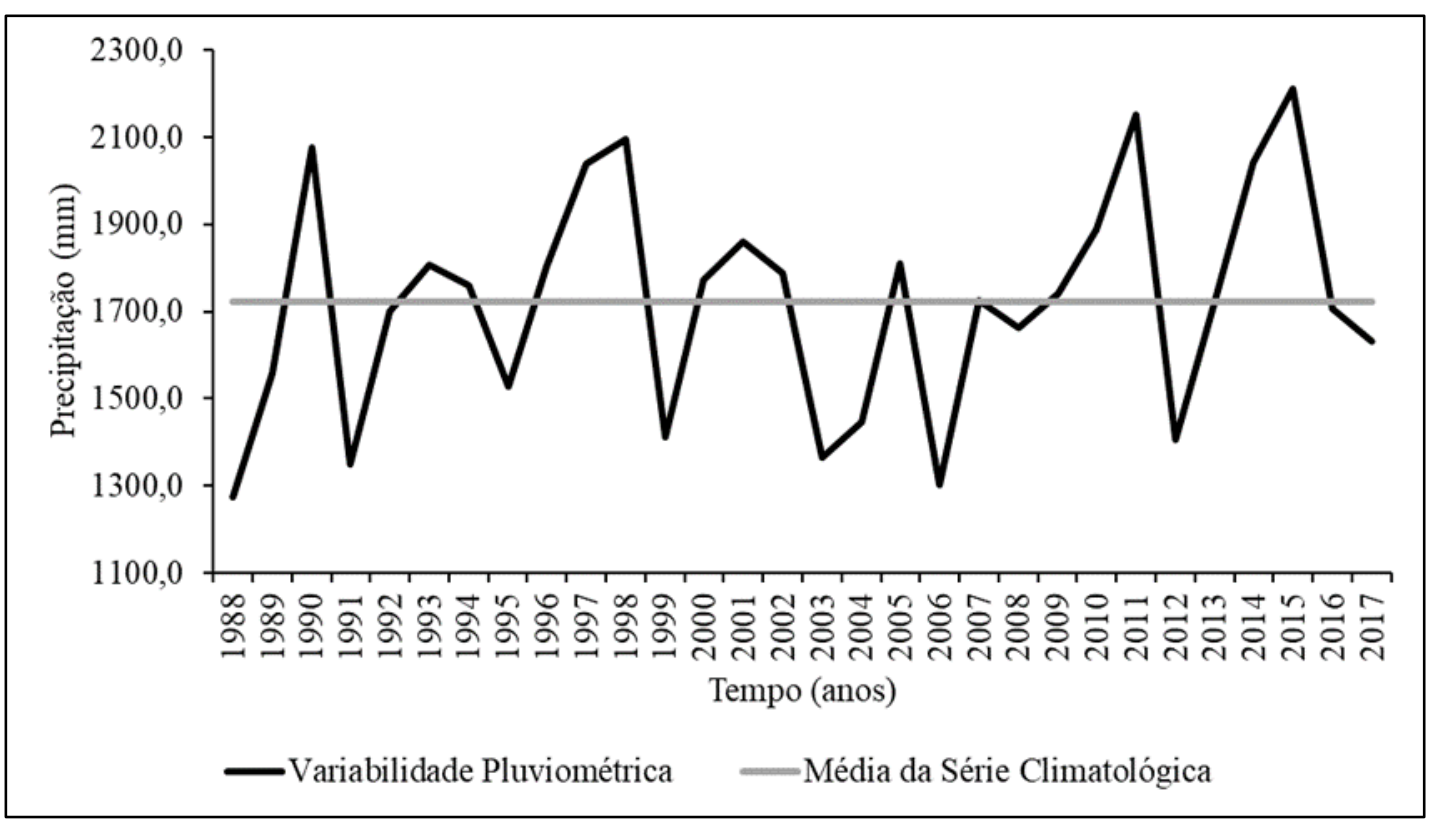

Fonte: ANA (2019). Adaptado por autor (2019) 
Na Fig. 4a é indicada a variabilidade média mensal pluviométrica (1988 2017), onde no Alto Canoas o trimestre mais chuvoso é observado em Setembro (170,0 mm), Outubro (181,6 mm) e Novembro (121,9 mm). Segundo o SNPDC (2020) Tempestades locais atingiram as populações das cidades de Lages (Novembro/2019) e Rio Rufino (Janeiro/2020). O trimestre menos chuvoso varia de Março (116,3 mm), Abril $(110,0 \mathrm{~mm})$ e Maio $(109,2 \mathrm{~mm})$. A ocorrência (Fevereiro/2020) de estiagem foi registrada no município de Abdon Batista (SNPDC, 2020). Na Fig. 4b destaca-se o IAC com época de estiagem (Mar-Ago), sendo classificados como um período Seco e o mês de agosto como o mais crítico apresentando escassez hídrica de - 0,77 (Baixo Canoas) e - 0,44 (Alto Canoas). O período Chuvoso (Set-Fev) é marcado pelo maior abastecimento pluviométrico anômalo em outubro de 1,20 (Baixo Canoas) e 0,91 (Alto Canoas).

Os valores elevados de chuva são decorrentes dos sistemas atmosféricos atuantes na região neste período. Dentre eles, destacam-se as Frentes frias que são massas de ar frio que adentram em determinado local onde predomina uma massa de ar relativamente mais quente e alteram as condições de tempo sobre a região, podendo gerar chuvas (SILVA et al., 2014), além de ser um dos principais sistemas precipitantes do sul do Brasil (CATTO et al., 2012). Há também a influência de Complexo Convectivo de Mesoescala (CCM), que é caracterizado por um aglomerado de nuvens convectivas, possuindo uma área contínua de precipitação, apresentando formato circular e provocando grandes volumes de chuva (MACHADO; ROSSOW, 1993). Figueiredo e Scolar (1996) verificaram que 70\% dos casos de CCM analisados por eles (25 casos) deslocaram-se para o sul do Brasil, atingindo o estado de Santa Catarina.

Observa-se na Fig. 5 a espacialização pluviométrica média anual (1988 2017) na bacia hidrográfica do rio Canoas. Os menores valores de precipitações são observados na porção Sul/Sudeste com variação de 1617,1 mm - 1750,1 mm, contribuindo com o abastecimento hídrico no Alto Canoas. Na região central da bacia (Médio Canoas) a pluviosidade oscila com totais de 1661,4 mm - 1750,1 mm. 
Os montantes pluviométricos concentram-se á norte/noroeste variando de 1750,1 $\mathrm{mm}-1883,1 \mathrm{~mm}$, auxiliando consideravelmente na recarga hídrica da foz do rio Canoas.

Figura 4 - (a) Variabilidade média mensal pluviométrica (1988 - 2017). (b) Índice de Anomalia de Chuva (IAC): estação Vila Canoas (Alto Canoas) e estação Passo Marombas (Baixo Canoas)

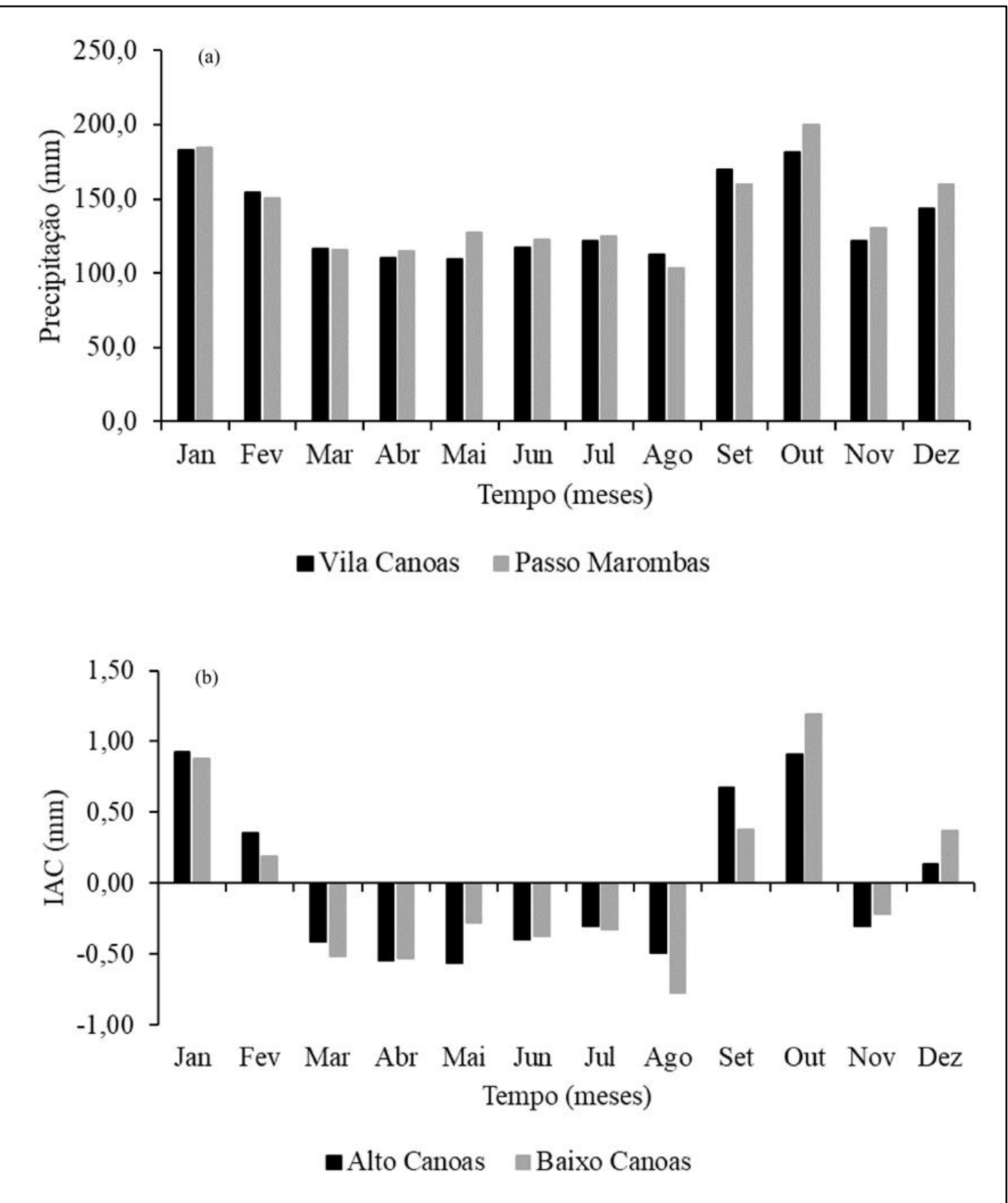

Fonte: ANA (2019). Adaptado por autor (2019) 
A climatologia de precipitação é fundamental para vários âmbitos na estrutura de manutenção da sociedade, contribuindo com atividades como as práticas agrícolas, gestão de recursos hídricos sob a ótica de análises de distribuição espacial e temporal da chuva (COSTA et al., 2012; RADHA e SUDHAKARAN, 2015). O entendimento do comportamento do clima associado à precipitação é necessário para o monitoramento dos períodos secos ou chuvosos, pois implica em atividades como abastecimento d'água das cidades e projetos de irrigação (FREITAS, 2004; FREITAS, 2005).

Figura 5 - Distribuição espacial da média anual pluviométrica (1988 - 2017): Bacia hidrográfica do rio Canoas

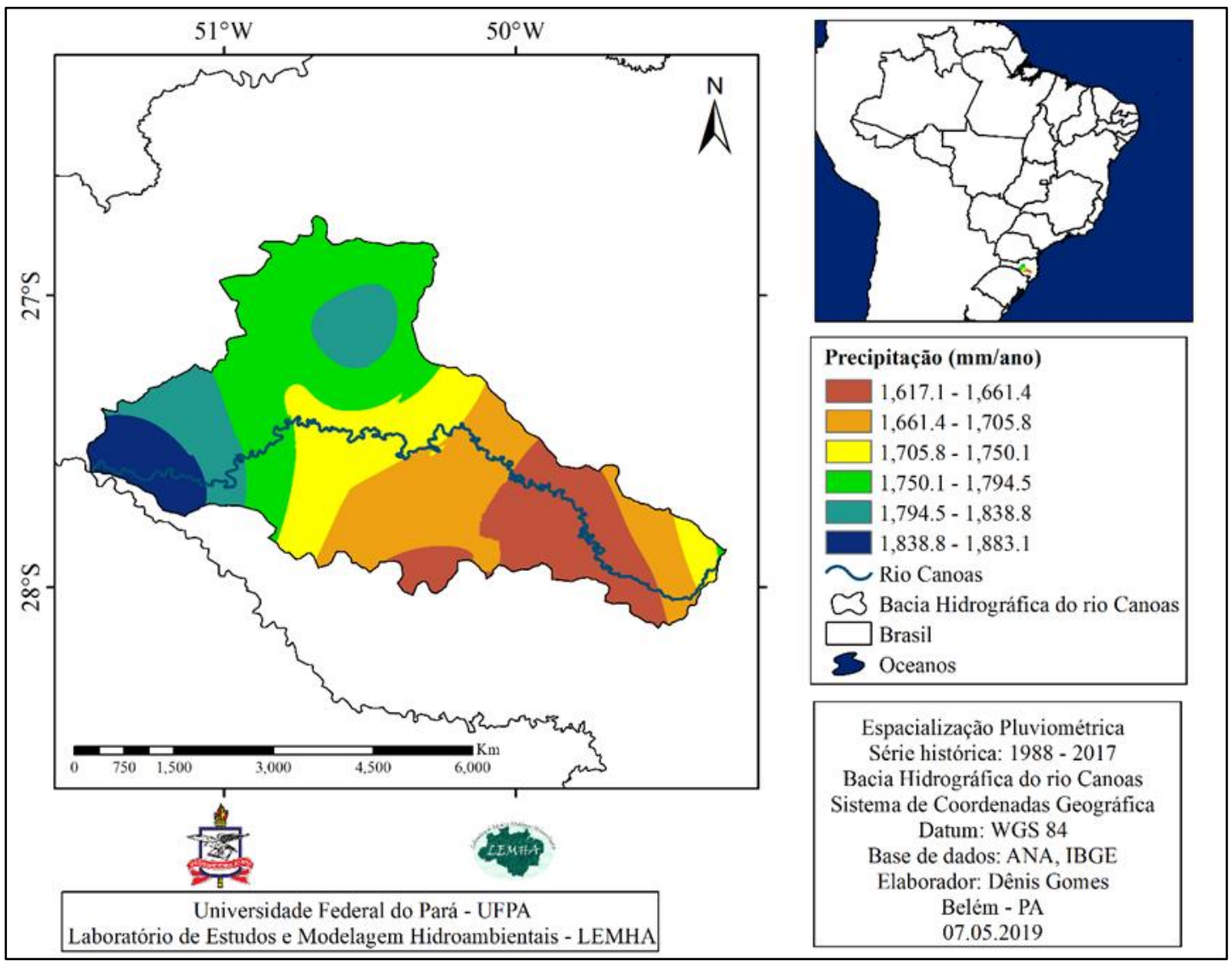

Fonte: ANA (2019). Adaptado por autor (2019)

Na Fig. 6 consta a variabilidade média sazonal da BHC, onde observa-se influência de sistemas sinóticos como passagem de frentes frias que contribuem para o abastecimento hídrico na região com precipitações intensas, assim como 
casos registrados de CMM's que favorecem no aumento pluvial da área. No período chuvoso (Set - Fev) observa-se precipitações que oscilam em torno de 139,8 mm 261,9 mm, este montante pluvial auxilia na recarga hídrica da região, principalmente no setor oeste da bacia.

Figura 6 - Distribuição espacial da média mensal pluviométrica (1988 a 2017): Bacia hidrográfica do rio Canoas

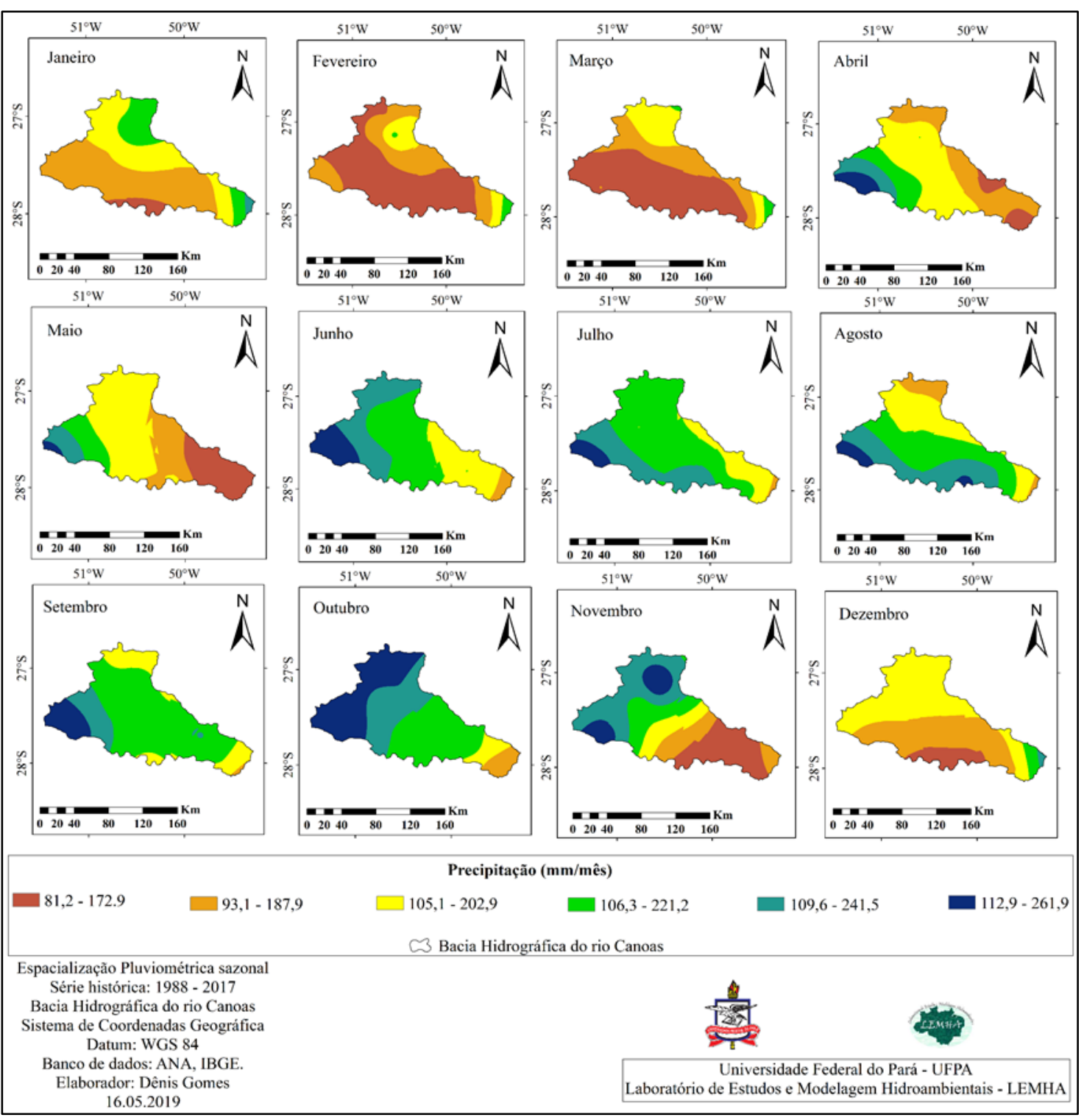

Fonte: ANA (2019). Adaptado por autor (2019)

O período de estiagem (Mar - Ago) é marcado pela diminuição da pluviosidade variando aproximadamente em $81,2 \mathrm{~mm}-177,1 \mathrm{~mm}$, sugerindo uma 
época vulnerável a eventos de secas e baixa disponibilidade hídrica na região. Simioni e Wollmann (2016) e Siqueira et al. (2018) apontam a importância do estudo da distribuição espacial e temporal pluviométrica para diversos setores que compõe a sociedade como agricultura, recarga hídrica dos mananciais superficiais e subterrâneos. Destaca-se a importância na para a análise de risco de ocorrência de desastres naturais, principalmente para a região em análise que já apresenta um histórico de eventos.

A Tab. 3 ilustra as ocorrências (2003-2016) de desastres naturais nos municípios da BHC. Identifica-se uma grande vulnerabilidade da região a eventos de estiagens com 81 casos (62,3\%) registrados dentre os 130 desastres contabilizados no período disponibilizado pela SNPDC (2020), sendo 72 (88,9\%) desses eventos ocorridos na estação de estiagem. Constatando que 59 casos (72,8 \%) de estiagens foram observados em anos de variações climáticas favoráveis a diminuição da precipitação com ênfase para 2006 com 24 eventos extremos de déficit hídrico.

Observou-se também um considerado número de cidades atingidas por 37 eventos (28,4 \%) de enxurradas, onde $22(59,4 \%)$ desses casos aconteceram no período chuvoso. Entretanto, 27 (73,0 \%) desses desastres aconteceram em anos desfavoráveis ao aumento da pluviosidade, sendo o ano de 2011 registrados 20 casos de enxurradas na BHC. Vale ressaltar que 13 cidades (52\%) afetadas situamse nos altos relevos e Barbosa et al. (2012) reforçam que regiões com elevado grau de declividade expostas a um intenso regime pluviométrico suscetibilizam a área á enxurradas. As enchentes e inundações houveram 6 e 5 episódios respectivamente na estação das chuvas com 10 casos (90 \%) ocorrendo sob condições climatológicas do acoplamento oceano-atmosfera desfavoráveis a formação de precipitação. Eventos de chuvas intensas foram observados somente 2 casos em Abdon Batista e Fraiburgo na época da estiagem, onde os moduladores climáticos podem estar relacionados a estes grandes volumes pluviométricos. 
Tabela 3 - Informações de registros de ocorrência de desastres naturais nos municípios da BHC

\begin{tabular}{|c|c|c|}
\hline Municípios/Desastres & Estação chuvosa & Estação da Estiagem \\
\hline Abdon Batista & Estiagens** & 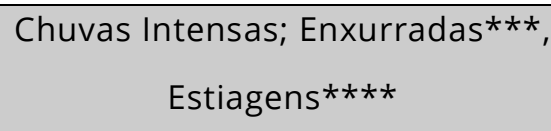 \\
\hline Anita Garibaldi & $\begin{array}{l}\text { Estiagens**, } \\
\text { Enxurradas** }\end{array}$ & Estiagens****, Enxurradas \\
\hline Bocaina do Sul & Inundações, Enchentes & Estiagem***, Enxurradas \\
\hline Bom Retiro & Enxurradas & Estiagem \\
\hline Brunópolis & Estiagem, Enxurradas** & Estiagens*****, Enxurradas \\
\hline Campos Novos & Estiagem, Enxurradas & Estiagens $* * * * *$, Enxurradas \\
\hline Correia Pinto & Enxurradas, Estiagem & Estiagem \\
\hline Curitibanos & & Estiagens*** \\
\hline Fraiburgo & & Chuvas Intensas, Estiagens*** \\
\hline Frei Rogério & Enxurradas & 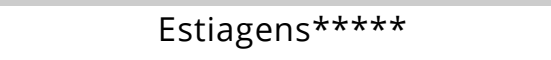 \\
\hline Monte Carlo & Enxurradas & Estiagens $* \star \star \star$ \\
\hline Lages & $\begin{array}{l}\text { Inundações**, } \\
\text { Enxurradas }\end{array}$ & Enxurradas, Estiagens** \\
\hline Leblon Régis & Enchentes & Estiagens*****, Enxurradas \\
\hline Otacílio Costa & Enchentes, Estiagem & Estiagens** \\
\hline Painel & Estiagem & Estiagens* \\
\hline Palmeira & & Estiagens** \\
\hline Ponte Alta & Enxurradas & Estiagens*** \\
\hline Ponta Alta do Norte & Enxurradas & Estiagens** \\
\hline Rio Rufíno & Enchentes, Enxurradas & Estiagens** \\
\hline Santa Cecília & Enchentes, Enxurradas & Enxurradas, Estiagem \\
\hline São Cristovão do Sul & & Estiagens** \\
\hline São José do Cerrito & Enxurradas*** & Estiagens $* * * * *$, Enxurradas \\
\hline Urubici & Enxurradas** & Enxurradas***, Estiagem \\
\hline Urupema & - & - \\
\hline Vargem & $\begin{array}{c}\text { Inundações, Enchentes } \\
\text { Enxurradas*** }\end{array}$ & Estiagens $* * \star * \star *$, Enxurradas \\
\hline
\end{tabular}

Fonte: SNPDC (2020). Adaptado por Autor (2019)

Em que: * Número de eventos extremos ocorridos 
A Fig. 7 apresenta a distribuição altimétrica da bacia hidrográfica do rio Canoas, onde ao norte e no setor leste (nascente do rio), encontra-se os maiores altiplanos com aproximadamente $1.818 \mathrm{~m}$. As menores altitudes da bacia são observadas ao longo de todo o rio Canoas até sua foz a sudoeste. A precipitação é influenciada pela orografia, pois este fator é uma forçante a ocorrência do processo de convecção do ar a barlavento da encosta montanhosa, aumentando a umidade do ar e seu levantamento, assim como a diminuição da temperatura do ar nesta região, suscetibilizando uma área para a formação de nuvens e intenso regime pluviométrico (MARCIEL et al., 2012; PEREIRA, 2013; BARATTO; WOLLMANN, 2015).

Na região do baixo curso do rio Canoas, nota-se que não há uma variação sazonal da precipitação, ressaltando a diferença de relevo considerável entre as duas sub-regiões. Souza e Galvani (2017) sugerem uma relação diretamente proporcional entre a altitude e a pluviosidade em uma bacia hidrográfica, seguindo este raciocínio a estação chuvosa no Baixo Canoas é caracterizada similar a região da nascente do rio, com os maiores regimes pluviais nos meses de Setembro $(159,7$ mm), Outubro (200,1 mm) e Novembro (130,6 mm), assim como a estação de estiagem é destacada no período de Março $(115,9 \mathrm{~mm})$, Abril $(114,8 \mathrm{~mm})$ e Maio $(127,3 \mathrm{~mm})$.

O padrão altimétrico da bacia indica uma área potencial de escoamento a norte, onde está localizada a estação de Passo Marombas, esta é condicionada por um relevo acidentado, correspondendo as mais altas cotas e maior gradiente de canal. O Alto Canoas (onde está a estação de Vila Canoas), apesar das elevadas topografias, tem uma geometria de vale mais aberta. Em ambos os casos existem possibilidades da ocorrência de acidentes vinculados as elevadas declividades e a incidência da precipitação pluviométrica. Esta grada de sudoeste para nordeste, mantendo ao longo do ano uma constante maior de chuvas (maio a novembro) na porção ocidental, e menor na região oriental. Nota-se que a bacia apresenta um eixo leste-oeste mais alongado que o norte-sul. O vale principal alonga-se segundo 
o maior eixo e a foz localiza-se na região de maior concentração de chuvas e a concentração das vazões totais da bacia.

Figura 7 - Carta altimétrica da bacia hidrográfica do rio Canoas

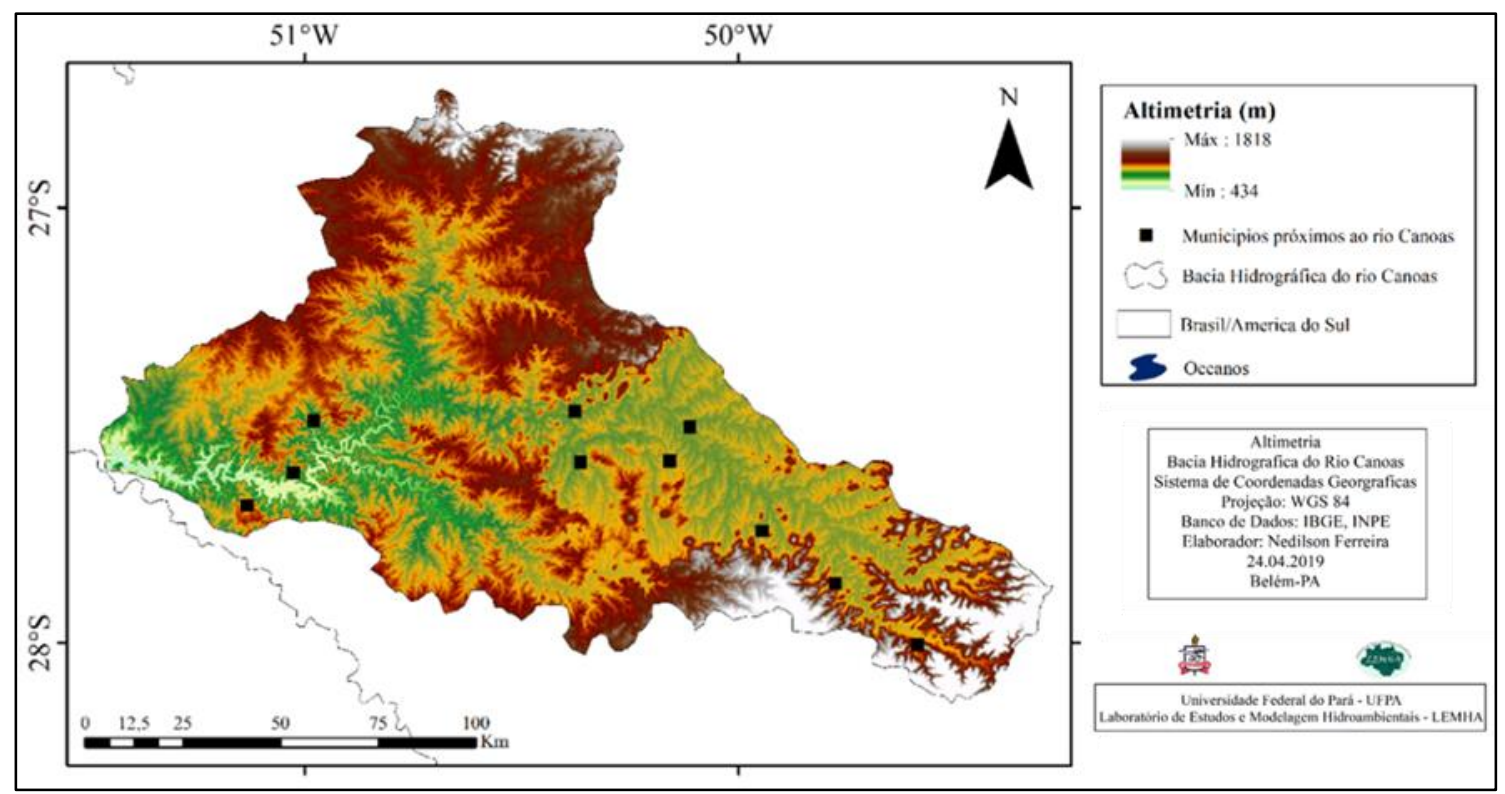

Fonte: INPE (2019). Adaptado por autor (2019)

O comportamento cota/vazão pode ser avaliado sob duas perspectivas. A primeira sendo a contribuição específica dos segmentos de bacia monitorados (Fig. 8), e a segunda tomando como base a vazão específica média de longo termo definida por Curtarelli et al. (2010) e Garbossa e Pinheiro (2015) para o estado de Santa Catarina.

A montante, observa-se uma flutuação irregular no nível d' água em todo o ano, destacando o trimestre das maiores cotas nos meses de Setembro $(257,2 \mathrm{~cm})$, Outubro $(266,3 \mathrm{~cm})$ e Novembro $(198,0 \mathrm{~cm})$ e o trimestre das menores cotas em Março (195,8 cm), Abril $(171,4 \mathrm{~cm})$ e Maio $(202,5 \mathrm{~cm})$. Na região próxima a jusante, há registro do trimestre das maiores lâminas d'águas em Setembro $(256,3 \mathrm{~cm})$, Outubro $(285,9 \mathrm{~cm})$ e Novembro $(248,8 \mathrm{~cm})$ e o trimestre das menores cotas em Março $(226,4 \mathrm{~cm})$, Abril $(218,5 \mathrm{~cm})$ e Maio $(231,4 \mathrm{~cm})$.

No Alto Canoas, o trimestre das maiores descargas fluviais compreende-se nos meses de Setembro (48,6 m3.s-1), Outubro (52,9 m3.s-1) e Novembro (32,4 
m3.s-1) e o trimestre das menores vazões foi em Março (32,2 m3.s-1), Abril (25,1 m3.s-1) e Maio (33,2 m3.s-1). Em Passo Marombas foi registrado as maiores vazões em Setembro (123,7 m3.s-1), Outubro (159,8 m3.s-1) e Novembro (105,3 m3.s-1) e o trimestre das menores descargas hídrica foi em Março (76,7 m3.s-1), Abril (72,1 m3.s-1) e Maio (90,7 m3.s-1). Esta variabilidade da vazão está diretamente relacionada com a oscilação da precipitação e cota, podendo ser observada a baixa defasagem e rápida velocidade do rio.

A aplicação da vazão específica média de longo termo para a bacia hidrográfica do rio Canoas apresentou o valor de $378,8 \mathrm{~m}^{3} / \mathrm{s}$, sendo a vazão específica 384,7 m³/s determinada pelo MINISTÉRIO DO MEIO AMBIENTE (2006). A mesma equação aplicada para os dois postos de medição obteve os valores de 29,0 $\mathrm{m}^{3} / \mathrm{s}$ para o Alto Canoas e de $106,6 \mathrm{~m} 3 / \mathrm{s}$ para o Baixo Canoas. Onde o desvio obtido para estas foi de - 29,3 \% para o Alto Canoas e de 4,4 \% para o Passo Canoas. Os valores positivos (negativos) significam que o valor médio da vazão observada é menor (maior) do que o obtido pela regionalização (GARBOSSA; PINHEIRO, 2015), representando um resultado que indica uma moderada aderência entre o valor regionalizado e o observado.

O monitoramento da vazão dos rios é de suma importância e vários estudos destacam os mais variados aspectos que esta variável hidrológica pode auxiliar na gestão dos recursos hídricos como na formação de modelos hidrológicos que podem contribuir na diminuição dos impactos causados por eventos extremos de estiagem e cheias, enxurradas, erosões fluviais (SILVA JUNIOR et al., 2017; FRANCO et al., 2018); logo a importância dos modelos de regionalização, uma vez que somente com uma proposta de monitoramento sistemático é possível prever o grau de amplitude das enchentes e suas consequências socioeconômicas e ambientais (CAVALCANTE, 2018; SOUZA et al., 2019).

O estudo de previsão de cheias em bacias hidrográficas de pequena extensão territorial é fundamental na relação natureza e sociedade, pois a falta de sistemas de alertas de cheias comentada por Cristaldo et al. (2018) pode causar 
danos irreparáveis em cidades próximas a rios susceptíveis a precipitações intensas.

Figura 8 - Variabilidade média mensal da fluviométrica (1988 - 2017): Estação Vila Canoas (Alto Canoas) e estação Passo Marombas (Baixo Canoas)

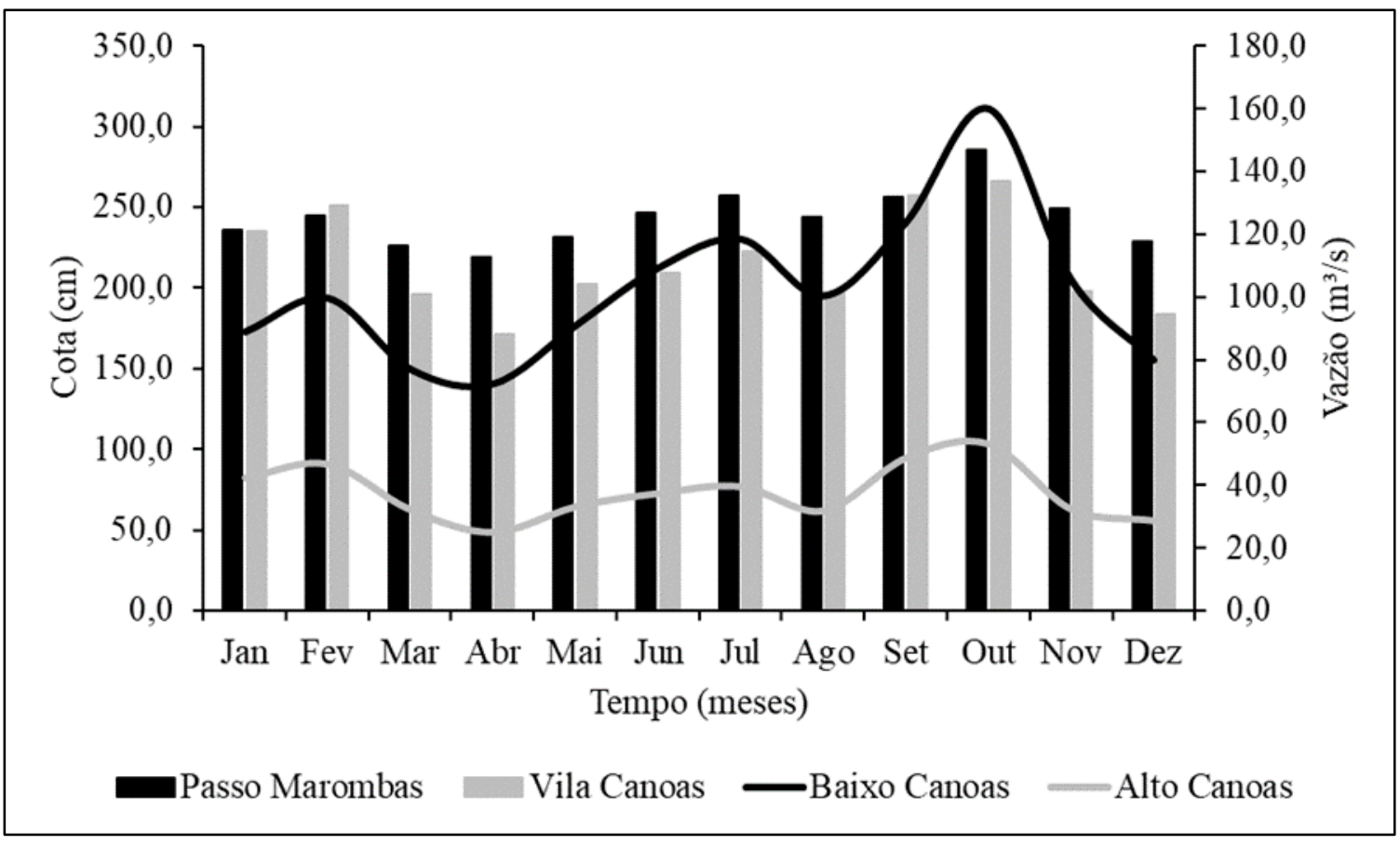

Fonte: ANA (2019). Adaptado por autor (2019). Cota (Linhas) e Vazão (Barras)

Comparando-se o comportamento chuva x vazão observa-se que não existe defasagem, sendo direto o reflexo das chuvas no comportamento das vazões nas estações analisadas. Este elemento é relevante para compreender os efeitos sob as formas de uso da terra e ocorrência de desastres naturais, que podem ser potencializados pelas mesmas.

Na concepção de Rodrigues et al. (2013) o entendimento sobre o processo de ocupação é fundamental no auxílio do ordenamento do uso e ocupação em bacias hidrográficas parar detectar áreas de vulnerabilidade ambiental que podem ser potencializadas por fatores antrópicos, a fim de apontar quais usos são mais adequados para que não cause impactos negativos significativos no equilíbrio hidrodinâmico da bacia hidrográfica. 
Na Fig. 9 destaca-se as diferentes formas de uso e ocupação na BHC segundo o Ministério do Meio Ambiente (2016), onde observa-se as seguintes categorias: Agricultura, Floresta, Hidrografia, Mosaico de ocupações e Pasto. A Agricultura é a classe de uso da terra de maior predominância na bacia, principalmente no setor oeste e sudeste da BHC com uma área de 11.390,9 km² (63,6 \%), região importante devido localizar-se o Alto e Baixo curso do rio Canoas. A Floresta é a segunda maior forma de cobertura em extensão, abrangendo uma área de aproximadamente $5.055,9 \mathrm{Km}^{2}$ (28,2 \%) com porções situadas ao norte e estendendo-se até o Médio curso do rio principal no qual prevalece na BHC. O Pasto atinge uma área em torno de 1.315,1 $\mathrm{km}^{2}$ (7,3\%), concentrando-se na parte sul da $\mathrm{BHC}$, sendo uma região que se encontra o maior mosaico de ocupações da BHC (município de Lages), ressaltando que esta categoria é observada sua distribuição ao longo de toda rede de drenagem atingindo uma área total de $138,6 \mathrm{Km}^{2}(0,7 \%)$.

Figura 9 - Formas de Uso e Ocupação do solo: Bacia Hidrográfica do rio Canoas

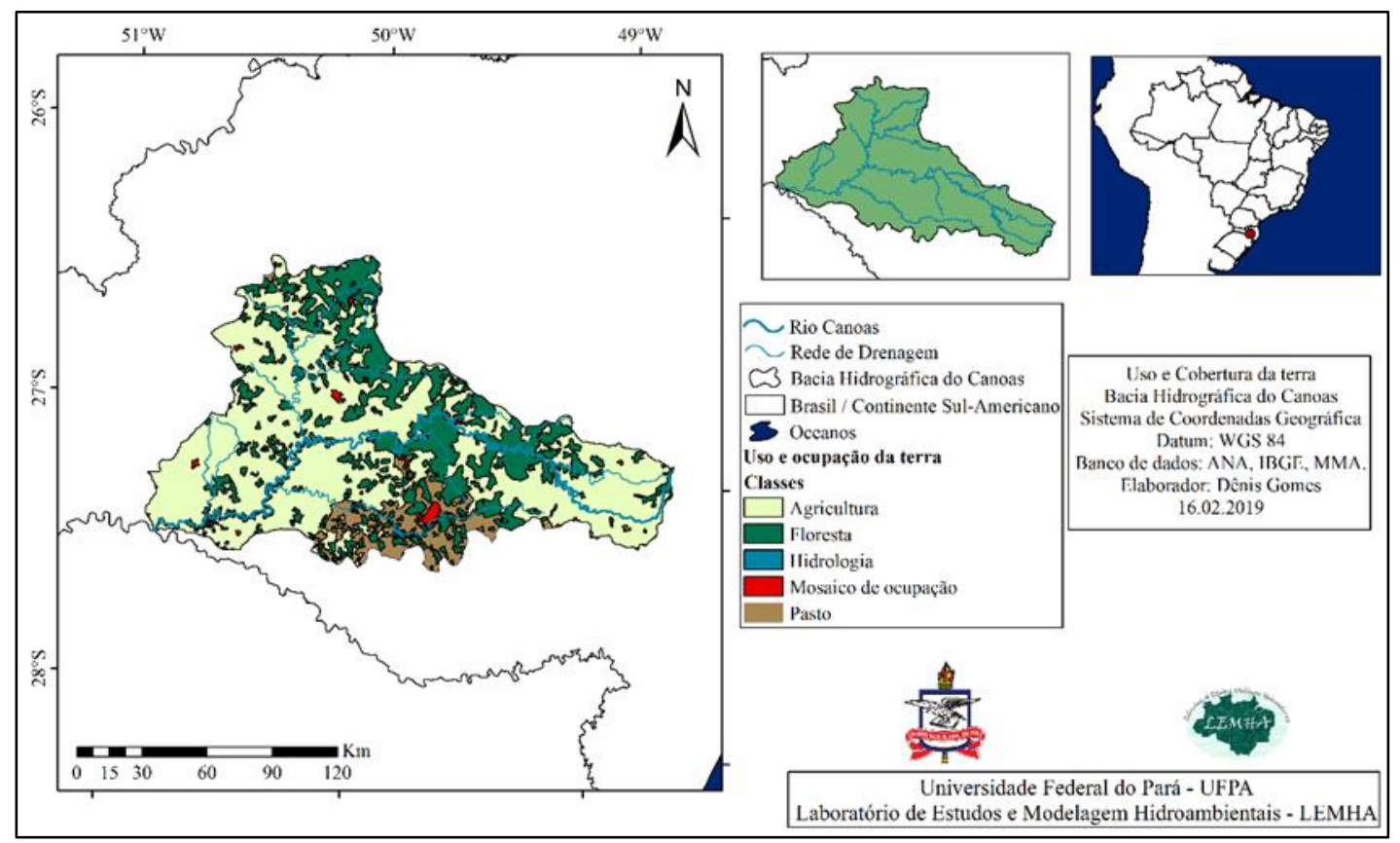

Fonte: Ministério do Meio Ambiente (2019). Adaptado por autor (2019)

A sub-bacia onde encontra-se a estação de Passo Marombas, apresenta o maior gradiente altimétrico e consequente potencial de escoamento superficial, porém observa-se que as áreas mais elevadas se encontram com manchas contínuas de cobertura vegetal, ainda que a presença de práticas agrícolas seja 
expressiva. O fato da maior proporção em área da bacia ter formas de uso associadas a expansão agropecuária e urbana, representa um fator de exposição do terreno aos processos erosivos, de origem fluvial e das chuvas. Assim, algumas cidades á noroeste que se situam em relevos acentuados apresentam formas de uso heterogêneas, sendo a retirada da vegetação (principalmente a riparia) o catalizador para o aumento de enxurradas oriundos de eventos extremos como descritas na Tab. 3.

A Tab. 4 mostra a relação estatística entre os índices climáticos e as variáveis hidrológicas segundo a correlação de Pearson ( $r$ ) e o coeficiente de determinação $\left(r^{2}\right)$. A correlação entre OAA x Precipitação e IOS x Precipitação apresentaram uma correlação positivamente baixa, ou seja, apesar de serem diretamente proporcionais sua força correlacional é pequena, assim como o grau de explicação entre estas variáveis. A relação AMM x Precipitação apresentam uma correlação positiva moderada para as águas oriundas do Atlântico, isto é, a intensidade da correlação é diretamente proporcional. A relação de dependência entre a Precipitação e o sistema fluviométrico da bacia hidrográfica apresentaram uma alta correlação positiva, isto é, quando a variável independente (precipitação) aumenta (diminui), a variável dependente (cota e vazão) aumenta (diminui) na mesma proporção. Ressalta-se o coeficiente de determinação entre a cota e vazão com 0,71 .

Tabela 4 - Estatística entre os índices climáticos e a hidrologia do rio Canoas (1988 2017): Estação Vila Canoas (Alto Canoas) e estação Passo Marombas (Baixo Canoas)

\begin{tabular}{ccccccc}
\hline & $\begin{array}{c}\text { OAA x } \\
\text { Precipitação }\end{array}$ & $\begin{array}{c}\text { AMM x } \\
\text { Precipitação }\end{array}$ & $\begin{array}{c}\text { IOS x } \\
\text { Precipitação }\end{array}$ & $\begin{array}{c}\text { Precipitação } \\
\text { x Cota }\end{array}$ & $\begin{array}{c}\text { Precipitação } \\
\mathbf{x} \text { Vazão }\end{array}$ & $\begin{array}{c}\text { Cota x } \\
\text { Vazão }\end{array}$ \\
\hline $\mathbf{r}$ & 0,30 & 0,53 & 0,24 & 0,80 & 0,79 & 0,99 \\
$\mathbf{r}^{2}$ & 0,09 & 0,29 & 0,06 & 0,64 & 0,64 & 0,71 \\
\hline
\end{tabular}

Fonte: Autor (2019) 
As relações obtidas traduzem o verificado na análise integrada dos produtos gerados:

(a) Precipitação x Cota; Precipitação x Vazão; Cota x Vazão:

Dada as dimensões da bacia e condições de uso e cobertura da terra, o balanço hídrico local teve uma boa correlação entre a chuva e a relação cota/vazão. As perdas existentes por infiltração, interceptação vegetal, e evapotranspiração representam as variações observadas. Paula et al. (2018) reforça que em bacias hidrográficas menores com baixa densidade de estações pluviométricas podem influenciar na representação espacial da precipitação.

(b) Precipitação e as componentes OAA, AMM e IOS:

A menor correlação entre estes indicadores e as taxas de precipitação, pode ser explicada pelo aspecto local das chuvas, que passa a ter influência mais continental, como exemplos citam-se a altimetria local e o fato da bacia do rio Canoas desaguar internamente na bacia do rio Pelotas. Cera e Ferraz (2015) afirmam ocorrem as influências remotas dos Oceanos Atlântico e Pacífico no regime das chuvas no Sul do Brasil, em escala global; o que corrobora com Lindemann e Justino (2018) que destacam que para a região dos extratrópicos do Hemisfério Sul (HS) o OAA é responsável por cerca de 35\% do total da variabilidade climática no HS.

No entanto, a correlação superior obtida entre o AMM e a precipitação demonstra a maior influência do Atlântico no regime pluviométrico do Brasil, reforçando discussões de alguns trabalhos (TASCHETTO; WAINER, 2008; BOMBARDI et al., 2014; HOUNSOU-GBO et al., 2019).

As condições climáticas de uma região atuam indiretamente e diretamente sobre a ecologia, paisagem e atividades econômicas da população, dentre os diversos fatores associados ao clima, a precipitação é a variável atmosférica que mais caracteriza o ambiente, por esta razão o monitoramento da variabilidade espaço-temporal da pluviosidade é essencial na manutenção de lugares vulneráveis a estas condicionantes climatológicas (GONÇALVES; BACK, 2018). Desta 
forma, para a melhor gestão preventivas de desastres naturais, faz-se necessário aprimorar o sistema de monitoramento da bacia hidrográfica do rio Canoas, uma vez que se constatou que o sistema ainda é pouco conhecido e precisa de atenção para evitar as consequências dos efeitos das cheias, influenciadas por eventos extremos de chuvas e deslizamentos de massa, principalmente nas regiões de maior gradiente altimétrico.

\section{CONCLUSÃO}

A bacia do rio Canoas apresenta uma variabilidade de respostas em função das condições hidroclimáticas, que segmenta bem o contexto de Alto e Baixo curso, tomando como base o maior eixo da bacia. Assim o regime hidrológico da região do Baixo Canoas (oeste da BHC) é o mais vulnerável a dinâmica climática, e isto agrava-se quando a grande área de agricultura presente e o elevado gradiente de relevo circundante favorecem um aumento do escoamento superficial podendo ocasionar eventos de enxurradas.

O extremo leste e oeste da BHC devem ser entendidos como áreas susceptíveis a riscos ambientais favorecidos por eventos extremos de chuvas e impulsionados pelas áreas agrícolas. Indicando a necessidade de alerta para os municípios de Abdon Batista, Anita Garibaldi, Campos Novos e Vargem que já foram atingidos por eventuais desastres, além do fator agravante de altos valores de regime pluviométrico. Considerando os limites mais a sul da bacia, onde se encontra o município de Lages, destaca-se que no período de Junho - Outubro, a ocorrência de chuvas concentradas eleva o sinal de alerta, isto agrava-se com a presença de áreas de pasto que favorecem o escoamento pluvial. Os extremos dos índices climáticos não são as maiores influências no regime hidrológico regional e o período de maior sensibilidade fluviométrica é setembro e outubro, favorecendo nesta época a ocorrência de cheias e inundações em municípios próximos aos rios.

Os desastres naturais mais frequentes na BHC são as estiagens e enxurradas, mostrando que medidas de prevenção quanto a escassez hídrica e ocupações inadequadas devem ser prioridade na gestão, assim como 
planejamento por parte dos órgãos competentes do uso dos recursos naturais. 0 monitoramento sistemático fluviométrico deve ser implantado, para cobertura do rio Canoas nos segmentos de médio e baixo curso, uma vez que dada a boa correlação chuva x vazão, a ampliação do número de observações pode ampliar as ações preventivas, principalmente durante o período mais chuvoso, aumentando a eficiência das redes de alerta.

\section{AGRADECIMENTOS}

Laboratório de Estudos e Modelagem Hidroambientais - LEMHA.

\section{REFERÊNCIAS}

ANA. Agência Nacional das Águas. Sistema Nacional de Informações sobre Recursos Hídricos. Disponível em: < http://www.snirh.gov.br/hidroweb/publico/apresentacao.jsf>. Acessado: 01 de Abril de 2019.

ANDRADE, M. A.; MELLO, C. R.; BESKOW, S. Simulação hidrológica em uma bacia hidrográfica representativa dos latossolos na região Alto rio Grande - MG. Revista Brasileira de Engenharia Agrícola e Ambiental, v. 17, n. 01, p. 69 - 76, 2013.

ARAÚJO, L. E.; MORAES NETO, J. M.; SOUSA, F. A. S. Classificação da precipitação anual de da quadra chuvosa da bacia do rio Paraíba utilizando índice de anomalia de chuva (IAC). Revista Ambiente e Água, v. 4, n. 3, p. 93-110, 2009.

BALBINOT, R.; OLIVEIRA, N. K.; VANZETTO, S. C.; PEDROSO, K. O papel da floresta no ciclo hidrológico em bacias hidrográficas. Revista Ambiência, v. 04, n .01, p. 131-149, 2008.

BARATTO, J.; WOLLMANN, C. A. Perfil topo-oro-pluviométrico do estado do Rio Grande do Sul. Revista Interface, Ed. 10, p. 44 - 55, 2015.

BARBOSA, F. T.; BERTOL, I.; WERNER, R. S.; RAMOS, J. C.; RAMOS, R. R. Comprimento crítico de declives relacionado à erosão hídrica, em três tipos e doses de resíduos em duas direções de semeaduras direta. Revista Brasileira de Ciência do Solo, v. 36, p. 1279-1290, 2012.

BOMBARDI, R.J.; CARVALHO, L. M. V.; JONES, C.; REBOITA, M. S. Atlantic sea surface temperature during neutral ENSO periods. Climates Dynamics, v. 42, p. 1553-1568, 2014. 
CAPOZZOLI, C. R.; CARDOSO, A. O.; FERRAZ, S. R. T. Padrões de variabilidade de vazão de rios nas principais bacias brasileiras e associação com índices climáticos. Revista Brasileira de Meteorologia, v. 32, n. 02, $243-254,2017$.

CATTO, J.; JAKOB, C.; BERRY, G.; NICHOLS, N. Relating global precipitation to atmospheric fronts. Geophysical Research Letters, v. 39, n. 10, p. 01 - 06, 2012.

CAVALCANTE, A. A. Distribuição temporal de descargas e alterações morfológicas em rios semiáridos: O rio Jaguaribe no Ceará, Brasil. Revista do Departamento de Geografia, v. 35, p. $28-36,2018$.

CATALDI, M.; ASSAD, L. P. F.; TORRES JUNIOR, A. R.; ALVES, J. L. D. Estudo da influência das anomalias da TSM do atlântico sul extratropical na região da confluência Brasil Malvinas no regime hidrometeorolóligico de verão do sul e sudeste do Brasil. Revista Brasileira de Meteorologia, v. 25, n. 04, p. 513 - 524, 2010.

CERA, J. C.; FERRAZ, S. E. T. Variações climáticas na precipitação no sul do Brasil no clima presente e futuro. Revista Brasileira de Meteorologia, v. 30, n. 01, p. 81, 2015.

CHENG, C. L.; SHALABH, S; GARG, G. Coefficient of determination of multiple measurement error models. Journal of Multivariate Analyses, v. 126, p. 137-152, 2014.

CORREA, M. G. G; GALVANI, E. Variabilidade Espacial e Sazonal da Precipitação Pluviométrica na Bacia Hidrográfica no Rio Piquiri - PR. Revista do Departamento de Geografia da Universidade de São Paulo, v. 34, p. 21 - 30, 2017.

CORREA, N. F.; RIBEIRO, V. O.; MIOTO, C. L.; PARANHOS FILHO; A. C. Obtenção de MDE corrigido para delimitação de bacia hidrográfica com auxílio de geotecnologias livres. Revista Anuário do Instituto de Geociências, v. 40, n. 01, p. 217 - 225.

COSTA, H. C.; MARCUZZO, F. F. N.; FERREIRA, O. M.; ANDRADE, L.R. Espacialização e Sazonalidade da Precipitação Pluviométrica do Estado de Goiás e Distrito Federal. Revista Brasileira de Geografia Física, v.5, n.1, p.87-100, 2012.

CREPANI, E.; MEDEIROS, J. S.; AZEVEDO, L. G.; HERNANDEZ FILHO, P.; FLORENZANO T. G.; DUARTE, V. Curso de sensoriamento remoto aplicado ao zoneamento ecológico-econômico. São José dos Campos: INPE, 2001, 25p.

CRISTALDO, M. F.; SOUZA, C. C.; JESUS, L.; OLIVEIRA, P. T. S.; PADOVANI. C. R.; VIGANO, H. H. G. Previsão probabilística de enchentes para uma pequena bacia hidrográfica do Pantanal. Revista Ambiente \& Água, v. 13, n. 04, p. 1 - 10, 2018.

CURTARELLI, M. P.; SILVA, D. J.; FERREIRA, C. M. Estudo do balanço hídrico na bacia do rio Canoas em Urubici, SC, Brasil: subsídio á proteção da zona de recarga direta do Sistema Aquífero Guarani. Revista Ambiente \& Água, v. 05, n. 03, p. 108 - 121, 2010. 
CURY, M. D.; PEZENTE, D. P.; GONÇALVES, F. N.; SUTIL, T.; MENEGASSO, J. D. Análise do índice de anomalia de chuva (IAC) á bacia hidrográfica do rio Urussanga/SC. Revista Tecnologia e Ambiente, v. 24, p. $71-80,2018$.

DIAS, G. F. M.; GOMES, D. J. C.; SERRÃO, E. A. O.; LIMA, A. M. M.; MIRANDA, S. B. A.; SILVAJUNIOR, J. A.; SOUSA, A. M. L. Associação entre os eventos de ENOS e a distribuição espaço-temporal da precipitação na bacia hidrográfica do rio Capim. Revista Brasileira de Climatologia, v. 26, n. 16, p. 521-524, 2020.

DULTRA, B. A.; ROMERO, H. Relação entre as variabilidades de baixa frequência com as precipitações sobre regiões de Itajaí (Santa Catarina, Brasil) e Copiapó (Atacama, Chile). Revista Caderno Geográficos, v. 36, 2017.

EMBRAPA. Empresa Brasileira de Pesquisas Agropecuárias. Sistema Brasileiro de Classificação de solos (SiBCS). Brasília-DF: EMBRAPA. p. 75, 2018.

FIGUEIREDO, J. C; SCOLAR, J. Estudo da trajetória dps sistemas convectivos de mesoescala na América do Sul. In: Congresso Argentino de Meteorologia e Congresso Latino-americano e Ibérico de Meteorologia, 7. Buenos Aires, 1996.

FERNANDES, D. S.; HEINEMANN, A. B.; PAZ, R. L.; AMORIM, A. O.; CARDOSO, A. S. Índices para a quantificação da seca. Santo Antônio de Goiás: Embrapa Arroz e Feijão, 2009.

FRANCO, V. S.; SOUZA, E. B.; LIMA, A. M. M.; SOUZA, A. L.; PINHEIRO, A. N.; DIAS, T. S.; AZEVEDO, F. M. Climatologia e previsão hidrológica de cheia sazonal do rio Xingu, Altamira - PA. Revista Brasileira de Climatologia, v. 22, n. 14, p. 01 - 19, 2018.

FRANCA, R. R.; MENDONÇA, F. A. A. Pluviosidade na Amazônia meridional: variabilidade e teleconexões extra-regionais. Revista Franco-Brasileira de Geografia, v. 29, n. 29, 2016.

FREITAS, M. A. S. A Previsão de Secas e a Gestão Hidroenergética: O Caso da Bacia do Rio Parnaíba no Nordeste do Brasil. In: Seminário Internacional sobre Represas y Operación de Embalses, v. 1. p. 1-1, 2004.

FREITAS, M. A. S. Um sistema de suporte à decisão para o monitoramento de secas meteorológicas em regiões semi-áridas. Revista Tecnologia, v. Supl., p. 84-95, 2005.

GARBOSSA, L. H. P.; PINHEIRO, A. Vazões de referência para gestão de bacias hidrográficas rurais e urbanas sem monitoramento. REGA, v. 12, n. 1, p. 43-52, 2015.

GOMES, D. J. C.; LIMA, A. M. M.; SOARES, C. S. T.; FERREIRA, N. S. Influência do uso e cobertura da terra associados a eventos climáticos em sistemas hidrometeorológicos. Revista Geográfica Acadêmica, v. 13, n. 02, p. 21-36, 2019.

GONÇALVES, F. N.; BACK, A. J. Análise da variação espacial e sazonal e de tendências na precipitação da região sul do Brasil. Revista de Ciências Agrárias, v. 41, n. 03, p. 592 - 602, 2018. 
GROSS, J. A.; CASSOL, R. Ocorrências de índices de anomalia de chuva negativos no estado do Rio Grande do Sul. Revista Geográfica Acadêmica, v. 09, n. 02, p. 21 - 33, 2015.

HOUNSOU-GBO, G. A. Dinâmica do Atlântico tropical e seus impactos sobre o clima ao longo da costa do nordeste do Brasil. Tese em Ciências Oceanográficas (Doutorado). Universidade Federal de Pernambuco (UFPE), Recife-PE, 2015.

HOUNSOU-GBO, G. A.; SERVAIN, J.; ARAÚJO, M.; CANIAUX, G.; BOURLÈS, B.; FONTENELE, D.; MARTINS, E. S. P. R. SST indexes in the tropical South Atlantic for forecasting rainy seasons in northeast Brazil. Atmosphere, v. 10, n. 6, p. 1-21, 2019.

INMET. Instituto Nacional de Meteorologia. Disponível em: < http://www.inmet.gov.br/portal/index.php?r=clima/normaisClimatologicas>. Acessado em: 11 de Maio de 2019.

INPE. Instituto Nacional de Pesquisas Espaciais. Disponível em: <http://www.webmapit.com.br/inpe/topodata/>. Acessado em: 04 de Abril de 2019.

LEDA, V. C.; POlONIO, V. D.; SARTORI, A. A. C.; NICOLETE, D. A. P.; CARVALHO, T. M.; ZIMBACK, C. R. L. Análise comparativa de mapas de declividade na bacia do Ribeirão da Prata em Lençóis Paulista-SP. In: Simpósio Brasileiro de Sensoriamento Remoto, 17. João Pessoa-PB, 2015.

LICCO, E. A.; MAC DOWELL, S. F. Alagamentos, enchentes, enxurradas e inundações: Digressões sobre seus impactos sócio econômicos e governança. Revista de Iniciação Científica, Tecnológica e Artística, v. 05, n. 03, 2015.

LINDEMANN, D. S.; JUSTINO, F. B. A influência dos modos de variabilidade climática na temperatura em superfície na Antártica. Revista Brasileira de Meteorologia, v. 30, n. 02, p. $214-222,2015$.

MACHADO, L. A. T.; ROSSOW, W.B. Structural characteristics and radiative properties of tropical cloud clusters. Monthly Weather Review, v. 121, p. 3234-3260. 1993.

MARCUZZO, F. F. N.; ROCHA, H. M.; MELO, D. C. R. Mapeamento da precipitação pluviométrica no bioma pantanal do estado do Mato Grosso. Revista GeoAmbiente, v. 16, p. 66 - 84, 2011.

MACIEL, S. A.; BARCELOS, B. F.; OLIVEIRA, L. A. A análise da influência da altitude na temperatura e na precipitação da mesorregião Norte de Minas - Minas Gerais. Região GeoNorte, Ed. Especial. v. 05, p. 250 - 261, 2012.

MARION, F. A.; SANTOS, E. B.; HENDGES, E. R. Análise de modelos digitais de elevação para modelagem do relevo no município de Francisco Beltrão - PR. Revista Geográfica Acadêmica, v. 09, n. 02, p. $50-60,2015$.

MMA. Ministério do Meio Ambiente. Caderno da Região Hidrográfica do Uruguai. Brasília, 2006. 
MMA. Ministério do Meio Ambiente - Brasil. Disponível em: http://mapas.mma.gov.br/i3geo/datadownload.htm. Acessado em 22 de Janeiro de 2019.

MUNIZ, L. S.; FILIZOLA JUNIOR, N. P. Proposta de metodologia de análise dos padrões de cotas fluviométricas da bacia do rio Madeira - Brasil. Revista GeoNorte, v. 03, n. 04, p. 1242 - 1254 , 2012.

NOAA. National Oceanic Atmospheric and Administration. Disponível em: < https://www.esrl.noaa.gov/psd/data/climateindices/list/>. Acessado: 17 de Maio de 2019.

NORONHA, G. C.; HORA, M. A. G. M.; SILVA, L. P. Análise do índice de anomalia de chuva para a microbacia de Santa Catarina/Cambiocó, RJ. Revista Brasileira de Meteorologia, v. 31, n. 01, $74-81,2016$.

OLIVEIRA, N. L.; MARCUZZO, F. F. N. Correlação da variação da temperatura na parte sul do oceano atlântico com o número de dias de precipitação pluviométrica do estado do Mato Grosso do Sul. Revista GeoAmbiente, n. 20, p. 61 - 82, 2013.

PAULA, S. C.; TASSI, R.; PICCILLI, D. G. A.; LORENZINI NETO, F. Influence of the rain gauge network on the performance of a hydrological lumped model applied at diferente basin scales. Revista Brasileira de Recursos Hídricos, v. 23, n. 45, p. 1-14, 2018.

PELUSO JUNIOR, V. A. O relevo do território catarinense. Revista GeoSul, v. 02, 1986, 08p.

PENEREIRO, J. C.; BADINGER, A.; MACCHERI, N. A.; MESCHIATTI, M. C. Distribuições de tendências sazonais de temperatura média e precipitação nos biomas brasileiros. Revista Brasileira de Meteorologia, v. 33, n. 01, p. 93-113, 2018.

PEREIRA, T. Influência do relevo na precipitação das regiões hidrográficas do litoral Norte de Alagoas. Revista GeoUSP - espaço e tempo, n. 33, p. 239 - 253, 2013.

RADHA, L. \& SUDHAKARAN, G. Spatial and Temporal Variation of Rainfall in Iraq. SSRG. International Journal of Applied Physics, v.2, n.2, March/April, 2015.

RAMÓN-VALENCIA， J. A.; PALACIOS-GONZÁLEZ, J. R.; SANTOS-GRANADOS, G. R.; RAMÓNVALENCIA, J. D. Early warning system on extrem weather events for disaster risk reduction. Revista Facultad de Ingeniería Universidad de Antioqua, v. 92, 80-87, 2019.

REIS, J. B. C.; PONS, N. A. D.; LOPES, E. S. S. Monitoramento e alerta de inundação no município de Itajubá (MG) por regressão polinomial. Revista de Geociências, v. 35, n. 01, p. 134 - 148, 2016.

RIBEIRO, J.; VIEIRA, R.; TÔMIO, D. Análise da percepção do risco de desastres naturais por meio da expressão gráfica de estudantes do projeto defesa civil na escola. Desenvolvimento e Meio Ambiente, v. 42, p. 202 - 223, 2017. 
RODRIGUES, R. S. S.; BITTENCOURT, G. M.; FERNANDES, L. L. Escoamento superficial em uma pequena bacia hidrográfica rural da Amazônia. Revista Brasileira de Cartografia, v. 70, n. 02, p. $605-628,2018$.

RIBEIRO, F. L.; CAMPOS, S. Vulnerabilidade á erosão do solo da região do Alto rio Pardo, Pardinho, SP. Revista Brasileira de Engenharia Agrícola e Ambiental, v. 11, n. 06, p. 628 636, 2007.

ROOY, M. P. V. A rainfall anomaly index independent of time and space. Notes. Weather Bureau of South Africa, v. 14, p. $43-48,1965$.

SELUCHI, M.; BEU, C.; ANDRADE, K. M. Características das frentes frias causadoras de chuvas intensas no leste de Santa Catarina. Revista Brasileira de Meteorologia, v. 32, n. 01, p. 25 37, 2017.

SILVA, D. F. Efeitos de José e Noé nas cotas do rio São Francisco. Revista Brasileira de Ciências Ambientais, v. 28, p. $66-75,2013$.

SILVA JUNIOR, R. O.; QUEIROZ, J. C. B.; FERREIRA, D. B. S.; TAVARES, A. L.; SOUZA FILHO, P. W. M.; GUIMARÃES, J. T. F.; ROCHA, E. J. P. Estimativa de precipitação e vazões médias para a bacia hidrográfica do rio Itacaiúnas (BHRI), Amazônia Oriental, Brasil. Revista Brasileira de Geografia Física, v. 10, n. 05, p. 1638 - 1654, 2017.

SILVA, L. J; REBOITA, M. S.; ROCHA, R. P. Relação da passagem de frentes frias na região sul de minas gerais (rsmg) com a precipitação e eventos de geada. Revista Brasileira de Climatologia, v. 14, p. $229-246,2014$.

SIMIONI, J. P. D.; WOLLMANN, C. A. Caracterização e variabilidade interanual da precipitação pluviométrica na estação ecológica do TAIM, Rio Grande do Sul, no período de 1996 a 2009. Revista Eletrônica Geoaraguaia, v. 06, n. 01, p. 01 - 18, 2016.

SIQUEIRA, B.; NERY, J. T.; MARTINS, G. Variabilidade sazonal da precipitação na bacia do Paraná em território brasileiro. Revista Brasileira de Climatologia, v. 23, p. 45 - 59, 2018.

SNPDC. Secretaria Nacional de Proteção e Defesa Civil - Sistema Integrado de Informações sobre Desastres Naturais (S2iD). Disponível em: https://s2id.mi.gov.br/. Acessado em: 05/03/2020.

SOUSA, A. C.; CANDIDO, L. A.; ANDREOLI, R. V. Variabilidade interanual da precipitação e fluxo de umidade sobre a Amazônia usando o QTCM. Revista Brasileira de Meteorologia, v. 33, n. 01, p. $41-56,2018$.

SOUZA, D. O.; LINO, J. F. L.; BERNARDES, T.; SATO, E. N.; FIRMINO, M. B. M. Padrões meteorológicos e morfológicos associados a eventos de inundação na bacia do rio Uruguai: estudo de caso para o município de Uruguaiana-RS. Revista Brasileira de Cartografia, Ed. Desastres Naturais e Impactos ambientais, n. 69/4, p. 621-633, 2017. 
SOUZA, R. S.; MOURA, J. M. S.; SILVA, R.; HOLMES, R. M.; PEUCKER-EHRENBRINCK, B.; SPENCER, R. B. M.; SOUSA, W. S. Aporte de carbono orgânico sob diferentes condições hidrológicas no rio Tapajós (PA), Amazônia, Brasil. Revista Geociências, v. 38, n. 01, p. 221 - 228, 2019.

SOUZA, V.; GALVANI, E. Distribuição espaço-temporal da precipitação pluvial e sua interação com o relevo na bacia do rio Jacaré Guaçu (SP). Revista Ciência e Natura, Ed. Espacial. v. 39, p. $110-124,2017$.

TASCHETTO, A. S.; WAINER, I. The impact of the subtropical South Atlantic SST on South american precipitation. Annales Geophysicae, v. 26, p. 3457-3476, 2008.

VALERIANO, M. M.; ROSSETTI, D. F.; Topodata: Brazilian full coverage refinement of SRTM data. Applied Geography (Sevenoaks), v. 32, p. 300-309, 2012.

\section{CONTRIBUIÇÃO DOS AUTORES}

\section{1 - Dênis José Cardoso Gomes}

Universidade do Estado do Pará (UEPA), graduado em Meteorologia (UFPA), Mestrando em Ciências Ambientais (UEPA).

https://orcid.org/0000-0001-6441-6783 - deniss.feg@gmail.com

Contribuições: Conceituação, investigação, metodologia, escrita - revisão e edição, visualização.

\section{2 - Camila do Socorro Teixeira Soares}

Universidade Federal do Pará (UFPA), graduada em Meteorologia (UFPA) https://orcid.org/0001-0001-8741-4959 - ca.milasoares@outlook.com.br Contribuição: investigação, escrita - revisão e edição.

\section{3 - Ingrid Cássia Porto Lima}

Universidade Federal do Pará (UFPA), graduada em Geografia (UFPA), Mestra em Gestão de Riscos e Desastres na Amazônia (UFPA). https://orcid.org/0000-0002-5777-8302 - ingrid.cassia@gmail.com Contribuição: investigação, escrita - revisão e edição.

\section{4 - Nedilson Sanches Ferreira}

Universidade Federal do Pará (UFPA), graduando em Meteorologia (UFPA) https://orcid.org/0000-0001-8338-9274 - nedilsonlive@gmail.com Contribuição: investigação, metodologia.

\section{5 - Aline Maria Meiguins de Lima}

Universidade Federal do Pará (UFPA), graduada em Geologia (UFPA), Especialista em Recursos Hídricos (UFPB), Mestra em Geotecnia (USP), Dr ${ }^{\mathrm{a}}$. em Desenvolvimento Socioambiental e Docente da UFPA. https://orcid.org/0000-0002-0594-0187 - ameiguins@ufpa.br 
Contribuições: supervisão, escrita - revisão e edição.

\section{Como citar este artigo}

GOMES, D.J.C.; SOARES, C. S.T.; LIMA, I.C.P.; FERREIRA, N.S.; LIMA; A.M.M. Oscilações hidroclimáticas associadas às condições ambientais: bacia hidrográfica do rio CanoasSC. Ciência e Natura, Santa Maria, v. 43, e62, p. 1-34, 2021. DOI 10.5902/2179460X43391. 